\title{
Multivariable Discriminant Analysis for the Differential Diagnosis of Microcytic Anemia
}

\author{
Eloísa Urrechaga, ${ }^{1}$ Urko Aguirre, ${ }^{2}$ and Silvia Izquierdo ${ }^{3}$ \\ ${ }^{1}$ Laboratorio, Hospital Galdakao-Usansolo, 48960 Galdakao, Vizcaya, Spain \\ ${ }^{2}$ Unidad de Investigación CIBER Epidemiología y Salud Pública, 48960 Galdakao, Vizcaya, Spain \\ ${ }^{3}$ Genética Clínica, Servicio de Bioquímica Clínica, Hospital Universitario Miguel Servet, 50009 Zaragoza, Spain
}

Correspondence should be addressed to Eloísa Urrechaga; eloisa.urrechagaigartua@osakidetza.net

Received 14 July 2013; Accepted 5 August 2013

Academic Editor: Aurelio Maggio

Copyright ( 2013 Eloísa Urrechaga et al. This is an open access article distributed under the Creative Commons Attribution License, which permits unrestricted use, distribution, and reproduction in any medium, provided the original work is properly cited.

\begin{abstract}
Introduction. Iron deficiency anemia and thalassemia are the most common causes of microcytic anemia. Powerful statistical computer programming enables sensitive discriminant analyses to aid in the diagnosis. We aimed at investigating the performance of the multiple discriminant analysis (MDA) to the differential diagnosis of microcytic anemia. Methods. The training group was composed of $200 \beta$-thalassemia carriers, $65 \alpha$-thalassemia carriers, 170 iron deficiency anemia (IDA), and 45 mixed cases of thalassemia and acute phase response or iron deficiency. A set of potential predictor parameters that could detect differences among groups were selected: Red Blood Cells (RBC), hemoglobin ( $\mathrm{Hb})$, mean cell volume (MCV), mean cell hemoglobin (MCH), and RBC distribution width (RDW). The functions obtained with MDA analysis were applied to a set of 628 consecutive patients with microcytic anemia. Results. For classifying patients into two groups (genetic anemia and acquired anemia), only one function was needed; $87.9 \% \beta$-thalassemia carriers, and $83.3 \% \alpha$-thalassemia carriers, and $72.1 \%$ in the mixed group were correctly classified. Conclusion. Linear discriminant functions based on hemogram data can aid in differentiating between IDA and thalassemia, so samples can be efficiently selected for further analysis to confirm the presence of genetic anemia.
\end{abstract}

\section{Introduction}

Iron deficiency anemia (IDA) and $\beta$-thalassemia are the most common causes of microcytic anemia.

The differentiation between IDA and microcytosis due to genetic cause has important clinical implications. As all chronic diseases, prevention is important in the overall management of the disease: an appropriate screening, detection of patients, and counsel of couples at risk are the most important procedures for the reduction of morbidity and mortality of the patients [1].

The presumptive identification of hemoglobin disorders must rely on inexpensive methods of detection, to allow an efficient use of the resources: a good method for screening can help, allowing selection of samples for further analysis to confirm the disease.

Definitive methods for diagnosis of thalassemia trait include quantitative analysis of $\mathrm{HbA}_{2}$ and DNA studies for specific deletions and mutations. Increased $\mathrm{HbA}_{2}$ is considered to be confirmatory for $\beta$-thalassemia trait. Low or normal values and no evidence of iron deficiency suggest $\alpha$-thalassemia; definitive diagnosis requires molecular methods to detect gene deletions. While being accurate, these tests are too expensive for initial mass screening [2].

The availability of computer, robotic systems, and powerful statistical software has expanded the accessibility of sophisticated statistical analysis. These include analyses employing multiple predictor variables (multivariate analysis) to predict an outcome variable [3].

MDA begins with subjects in two or more groups and then uses the discriminant procedure to identify a linear combination of quantitative predictor variables that best characterize the differences among the groups. The discriminant function sums the products of variables multiplied by coefficients. The procedure estimates the coefficients for each 
variable, and the resulting function can be used to classify new patients.

MDA can be used to develop more sensitive and accurate diagnostic methods for thalassemia detection using the data of the hemogram. We applied stepwise MDA to determinate which red cells derived parameters that are best in differentiating the heritable genetic anemia and the iron deficient state.

The aim of the present study was to investigate the performance of MDA to the differential diagnosis of genetic and acquired microcytic anemia, so samples can be efficiently selected for further analysis to confirm the presumptive diagnosis of thalassemia.

\section{Materials and Methods}

2.1. Criteria for Selecting the Groups of Patients. The study was conducted according to the hospital ethic's guidelines after being approved by the Committee of Ethics and Good Practice of the hospital.

Only adults were included in the present study, and none of them received a transfusion nor had an acute bleeding in the previous month. The samples were obtained in the course of routine analysis, collected in EDTA anticoagulant tubes (Vacutainer Becton-Dickinson, Rutherford, NJ, USA), and run in the analyzers of the LH 1500 Beckman Coulter robotic system (Beckman Coulter Inc., Miami, FL, USA) within 6 hours of collection.

A total of 480 patients were included in the training set, classified into four different disorders: IDA, $\alpha$ - and $\beta$-thalassemia, and a group of thalassemia carriers with other diseases at the moment of the analysis (mixed group).

The IDA group consisted of 170 patients (35.4\%), with $\mathrm{Hb}<120 \mathrm{~g} / \mathrm{L}, \mathrm{MCV}<80 \mathrm{fL}$, serum Iron $<7.5 \mu \mathrm{mol} / \mathrm{L}$, transferrin saturation $<20 \%$, and serum ferritin $<50 \mu \mathrm{g} / \mathrm{L}[4]$.

Two hundred $\beta$-thalassemia carriers (41.6\%) and 65 $\alpha$-thalassemia carriers (13.5\%), all of them with a previous diagnosis of the disease, were recruited.

A mixed group (9.5\%) included 45 thalassemia carriers with acute phase response (APR), iron deficiency, or pregnancy at the moment of the analysis.

Thalassemia screening is routinely performed in our laboratory by means of the measure of their Red Blood Cell parameters. Samples with erythrocytosis $\left(\mathrm{RBC}>5.5 \cdot 10^{12} / \mathrm{L}\right)$ and microcytosis (MCV $<80 \mathrm{fL}$ ) are selected for $\mathrm{HbA}_{2}$ quantification (HPLC HA 8160, Menarini Diagnostics, Firenze, Italy). Increased $\mathrm{HbA}_{2}(>3.5 \%)$ is considered to be confirmatory for $\beta$-thalassemia trait.

Low $\mathrm{HbA}_{2}(<2.5 \%)$ or a value within the reference range $(2.5 \%-3.5 \%)$ is feature of $\alpha$-thalassemia, and these samples are referred for molecular analysis to detect the associated deletions.

Molecular analysis is performed if genetic counsel is required. Molecular characterization of mutations is performed with allele specific oligonucleotide-polymerase chain reaction PCR-ASO techniques $[5,6]$.

A second group of consecutive patients with microcytic anemia $(n=628)$, extracted from the laboratory workload during the months of January and February 2013, was used as a validation set.
This group consisted of 505 (80.4\%) IDA patients, 63 (10.0\%) $\beta$-thalassemia, $16(2.6 \%) \alpha$-thalassemia, and 44 $(7.0 \%)$ a mixed group of hemoglobinopathies or thalassemia carriers with APR, IDA, or pregnancy at the moment of the analysis: $4 \alpha$-thalassemia and IDA, $3 \alpha$-thalassemia and APR; 1 pregnant $\alpha$-thalassemia carrier, $7 \beta$-thalassemia and IDA, 5 $\beta$-thalassemia and APR; 5 pregnant $\beta$-thalassemia carriers, 10 $\mathrm{Hb} \mathrm{S}$, and $4 \mathrm{Hb}$ Lepore; $1 \mathrm{Hb} \mathrm{E} ; 1 \mathrm{Hb} \mathrm{C}$ and IDA; $1 \mathrm{Hb} \mathrm{S}$ and APR; and 2 pregnant $\mathrm{HbS}$.

2.2. Statistical Analysis. A set of potential predictor parameters that could detect differences among the mentioned microcytic anemias were selected: Red Blood Cells (RBC), hemoglobin $(\mathrm{Hb})$, mean cell volume (MCV), mean cell hemoglobin $(\mathrm{MCH})$, and red cells distribution width (RDW).

The outcome of interest was the type of microcytic anemia. It was considered in two different ways: classification type I (IDA, $\alpha$-thalassemia, $\beta$-thalassemia, and mixed clinical situations) and classification type II (genetic anemia and IDA acquired anemia).

In the training group, as initial step, an exploratory data analysis of the collected hemogram parameters was performed across the type of disease, using means and standard deviations. To assess mean differences in the mentioned predictor parameters across the different types of disorders according to the classification type I, KruskallWallis nonparametric test for independent samples was used; Wilcoxon nonparametric test was used when classification type II was regarded.

Multivariate discriminant analysis (MDA) was conducted in order to distinguish differences among groups of diseases and to determine how to allocate new observations into the established groups. To this end, the above-mentioned parameters were considered as independent variables whereas the type of disease was the outcome. As the first step, Wilk's Lambda statistic was used to test whether the discriminant model was significant. Moreover, the number of discriminant functions, the corresponding standardized discriminant coefficients, and canonical correlations for each of studied parameters-the ones which maximized the distance between the groups-were also obtained. Correlations higher than 0.40 were considered significant [3].

Thereafter, a classification functional equation was constructed. A case was predicted as being member of the group in which the value of its classification function was the largest. The predicted diagnoses were then compared with the actual diagnoses in each of the original patients. Correct classification was defined as the division between concordant cases (when predicted and actual diagnoses were the same) and the entire sample size. This was performed by means of cross-validation. A scatterplot of the discriminant functions in the training set was depicted.

The validation set of 628 subjects was employed to evaluate the performance of the classification determined by the established functions in the training group.

All these statistical analyses where performed for the two mentioned classification types I and II, using the $R$ statistical software 2.14 release. A $P$ value $<0.05$ was deemed to be statistically significant. 


\section{Results}

There were significant differences for the disease group distribution in both data sets $(P<0.001)$.

Table 1 reports mean and standard deviations by disease groups. All analyzed blood markers showed significant mean differences among disease groups. Patients with IDA had the lowest values of $\mathrm{RBC}$ and $\mathrm{Hb}$ and the highest values of MCV.

Table 2 shows the standardized canonical coefficients obtained from the linear discriminant analysis.

MDA analysis for classifying patients into four groups (classification type I) illustrated that two canonical discriminant functions 1 and 2 cumulatively accounted for $99.85 \%$ of the total variance ( $P<0.001$ for both functions). In the first function, RBC was negatively correlated with the first function. The rest of variables ( $\mathrm{Hb}, \mathrm{MCV}$, and $\mathrm{MCH}$ ) showed negative and significant standardized loadings for the second function.

When classifying patients into two groups (genetic anemia and acquired iron deficiency anemia, classification type II), only one function was needed. In this case, RBC was positively correlated to the discriminant function.

Figure 1 shows the linear discriminant plot for the classification type I and the boxplot according the function obtained for the classification type II. In the discriminant plot, there is a significant overlap in the classes corresponding to diseases targeted as $\alpha$ - and $\beta$-thalassemia and the mixed group of thalassemia carriers, whereas patients with IDA are mostly separated from the others $(P<0.001)$. When classifying diseases as acquired or genetic anemia, again there is a clear separation between both blood disorders.

Once linear discriminant functions were calculated according to the results showed in Table 2, we computed the correct classification rates in the validation set for the entire samples and stratified by disease group.

Tables 3 and 4 display the obtained results. As one can observe in the validation set, when classification type I is applied, $70.3 \%$ of IDA disorders were correctly classified, and also $\alpha$-thalassemia had a high rate of correct classification $(68.8 \%)$; on the other hand only one-third of $\beta$-thalassemia was recognised, with $39.7 \%$ classified as $\alpha$-thalassemia; also one-third of the mixed group of genetic anemia was included in the IDA group.

When trying to classify diseases into two groups (genetic anemia versus IDA, classification type II), the overall rate surpassed the $85 \%$ rate $(87.9 \% \beta$-thalassemia carriers and $83.3 \% \alpha$-thalassemia carriers).

Nineteen $\%$ of the patients with genetic anemia were misclassified. Out of these patients, $5(20.8 \%)$ were $\beta$-thalassemia carriers and $4(16.7 \%) \alpha$-thalassemia, and $15(62.5 \%)$ were mixed group ( $5 \beta$-thalassemia and IDA, 5 $\alpha$-thalassemia and IDA, 1 pregnant $\alpha$-thalassemia, $2 \mathrm{Hb} \mathrm{S}$, and 2 pregnant $\mathrm{HbS}$ ).

\section{Discussion}

The screening of thalassemia carriers in endemic areas remains a daily challenge for laboratory professionals. Although thalassemia is most frequent in the Mediterranean

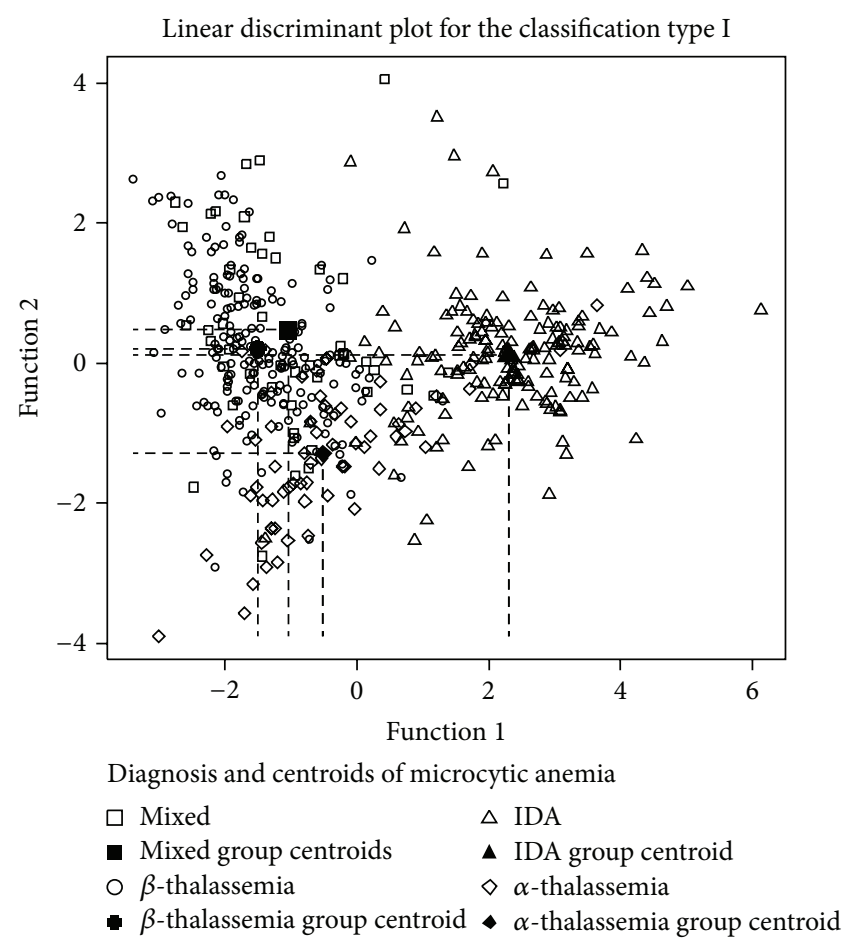

(a)

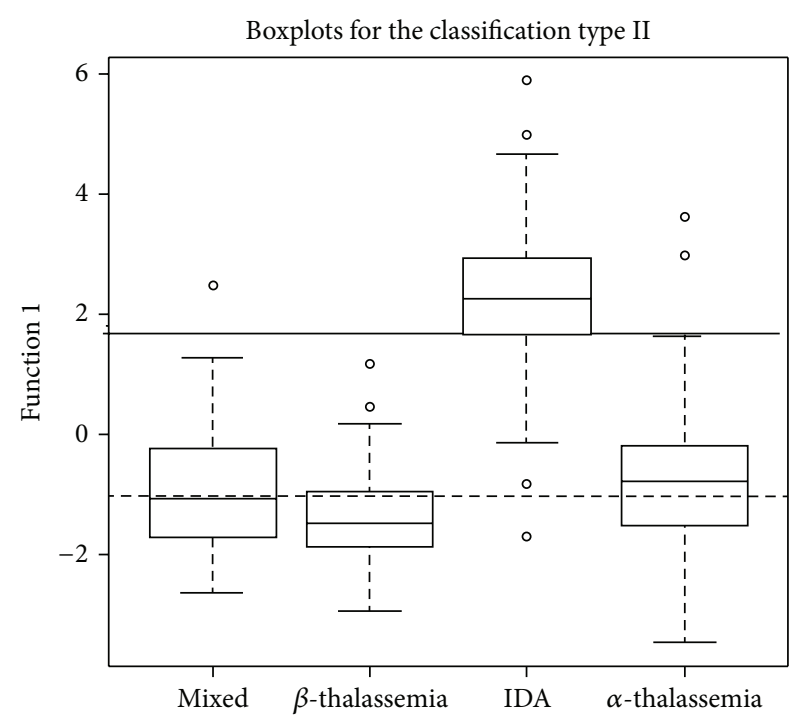

(b)

FIgURE 1: Linear discrimination plot for the studied classification type I (a) and boxplot for the classification type II in the training set (b). Black symbols in the linear discriminant plot indicate centroid groups. Dashed line in the boxplot reflects the cut-off value for the required discriminant function.

basin and Far East countries, due to migration of populations, there is virtually no country in the world now in which thalassemia does not affect some percentage of the inhabitants [7].

On the basis of classical hematological parameters, subjects with IDA are inappropriately discriminated from subjects with anemia due to thalassemia or chronic disease. 
TABLE 1: Hematological and biochemical data for the study patients comprised 170 with iron deficiency anemia (IDA), $200 \beta$-thalassemia carriers, $65 \alpha$-thalassemia carriers, and 45 mixed clinical situations (hemoglobinopathy and other disease, iron deficiency, or pregnancy). Values are reported as mean (standard deviation).

\begin{tabular}{|c|c|c|c|c|c|}
\hline & Mixed $^{\mathrm{a}}$ & $\beta$-thalassemia ${ }^{\mathrm{b}}$ & $\mathrm{IDA}^{\mathrm{c}}$ & $\alpha$-thalassemia ${ }^{\mathrm{d}}$ & $P$ value \\
\hline $\mathrm{RBC}, 10^{12} / \mathrm{L}$ & $\begin{array}{c}5.70 \\
(0.57)^{\mathrm{c}, \mathrm{d}}\end{array}$ & $\begin{array}{c}5.79 \\
(0.54)^{\mathrm{c}, \mathrm{d}}\end{array}$ & $\begin{array}{c}4.72 \\
(0.48)^{\text {all }}\end{array}$ & $\begin{array}{c}5.40 \\
(0.55)^{\text {all }}\end{array}$ & $<0.001$ \\
\hline $\mathrm{Hb}, \mathrm{g} / \mathrm{L}$ & $\begin{array}{c}116 \\
(13.2)^{\mathrm{d}}\end{array}$ & $\begin{array}{c}119 \\
(11.2)^{\mathrm{d}}\end{array}$ & $\begin{array}{c}105 \\
(11.0)^{\mathrm{c}, \mathrm{d}}\end{array}$ & $\begin{array}{c}123 \\
(14.0)^{\text {all }}\end{array}$ & $<0.001$ \\
\hline $\mathrm{MCV}, \mathrm{fL}$ & $\begin{array}{c}64.6 \\
(4.08)^{\mathrm{c,d}}\end{array}$ & $\begin{array}{c}64.6 \\
(3.39)^{\mathrm{c}, \mathrm{d}}\end{array}$ & $\begin{array}{c}73.7 \\
(4.63)^{\text {all }}\end{array}$ & $\begin{array}{c}70.5 \\
(2.96)^{\text {all }}\end{array}$ & $<0.001$ \\
\hline $\mathrm{MCH}, \mathrm{pg}$ & $\begin{array}{c}20.4 \\
(1.48)^{\mathrm{c}, \mathrm{d}}\end{array}$ & $\begin{array}{c}20.6 \\
(1.11)^{\mathrm{c}, \mathrm{d}}\end{array}$ & $\begin{array}{c}22.3 \\
(1.86)^{\mathrm{a}, \mathrm{b}}\end{array}$ & $\begin{array}{c}22.7 \\
(1.08)^{\mathrm{a}, \mathrm{b}}\end{array}$ & $<0.001$ \\
\hline RDW, \% & $\begin{array}{c}16.9 \\
(1.84)^{\mathrm{c}}\end{array}$ & $\begin{array}{c}16.1 \\
(1.06)^{\mathrm{c}}\end{array}$ & $\begin{array}{c}18.2 \\
(3.03)^{\text {all }}\end{array}$ & $\begin{array}{c}15.9 \\
(1.51)^{c}\end{array}$ & $<0.001$ \\
\hline
\end{tabular}

RBC: Red Blood Cells; Hb: hemoglobin; MCV: mean cell volume; MCH: mean cell hemoglobin; RDW: RBC distribution width. Superscript letters $\left({ }^{\mathrm{a}, \mathrm{b}, \mathrm{c}, \mathrm{d}, \mathrm{all}}\right)$ indicate significant differences between groups.

$P<0.001$ was for the studied blood markers for the mean differences between acquired (IDA) and genetic anemia.

TABLE 2: Standardized canonical coefficients obtained from the linear discriminant analysis.

\begin{tabular}{|c|c|c|c|c|c|c|}
\hline & \multicolumn{4}{|c|}{ Classification type I } & \multirow{2}{*}{\multicolumn{2}{|c|}{$\begin{array}{l}\text { Classification type II } \\
\text { First function }\end{array}$}} \\
\hline & \multicolumn{2}{|c|}{ First function } & \multicolumn{2}{|c|}{ Second function } & & \\
\hline & $\begin{array}{c}\text { Standardized } \\
\text { coefficient }\end{array}$ & $\begin{array}{c}\text { Relative } \\
\text { importance }\end{array}$ & $\begin{array}{c}\text { Standardized } \\
\text { coefficient }\end{array}$ & $\begin{array}{c}\text { Relative } \\
\text { importance }\end{array}$ & $\begin{array}{c}\text { Standardized } \\
\text { coefficient }\end{array}$ & $\begin{array}{c}\text { Relative } \\
\text { importance }\end{array}$ \\
\hline $\mathrm{RBC}$ & 0.902 & $-0.532^{*}$ & 5.481 & 0.154 & 1.778 & $0.537^{*}$ \\
\hline $\mathrm{Hb}$ & -1.362 & -0.332 & -5.723 & $-0.410^{*}$ & -2.225 & 0.284 \\
\hline $\mathrm{MCV}$ & 1.607 & 0.609 & 0.481 & $-0.636^{*}$ & 1.814 & $-0.361^{*}$ \\
\hline $\mathrm{MCH}$ & -0.257 & 0.292 & 2.408 & $-0.788^{*}$ & 0.152 & $-0.529^{*}$ \\
\hline RDW & 0.461 & 0.267 & 0.064 & 0.268 & 0.441 & 0.237 \\
\hline Proportion of trace (\%) & \multicolumn{2}{|c|}{91.26} & \multicolumn{2}{|c|}{8.59} & \multicolumn{2}{|c|}{100} \\
\hline
\end{tabular}

RBC: Red Blood Cells; Hb: hemoglobin; MCV: mean cell volume; MCH: mean cell hemoglobin; RDW: RBC distribution width.

First function: first linear discrimination function. Second function: second discrimination function. Classification type I: disease groups categorized into four diseases: mixed, $\beta$-thalassemia, $\alpha$-thalassemia, and IDA. Classification type II: targeted diseases as genetic anemia (mixed, $\beta$-and $\alpha$-thalassemia) and acquired anemia.

Standardized coefficient: standardized coefficient obtained from the linear discriminant analysis of each blood marker for the considered functions.

Relative importance: correlations of each variable with each discriminant functions.

${ }^{*}$ A correlation higher than 0.40 is considered significant.

Proportion of trace (\%): proportion of variability of the outcome explained by the considered independent variables.

Some indices have been defined to quickly discriminate both diseases based on the red cell parameters obtained from automated blood cell analyzers and are used as a preliminary screening, with matter of great interest in geographic areas where nutritional deficiencies and thalassemia are present with high prevalence [8].

There has been a clear revival of interest in the detection of thalassemia demonstrated by the increasing number of publications reporting new indices in recent years [9-12].

These cell counter-based formulae have been used in the differential diagnosis of microcytic anemia and $\beta$-thalassemia detection, but when applied to the detection of $\alpha$ thalassemia, or in case of thalassemia and concomitant iron deficiency, these formulae perform much less accurately.

Another approach to assist in classification of anemia has been the use of computer based expert system subset of artificial intelligence; mimicking the human expert the system applies decision trees, logic rules, or statistical best fit analysis to reach conclusions [13-16].

MDA approach fits fine with the realistic situation a mixed population. An advantage is the simplicity of application; once calculated, the formulae can be incorporated into a programmable calculator or computer spreadsheet, allowing insertion of the hemogram data of certain patients to obtain the provisional classification.

Eldibany et al. [17] applied MDA and identified MCH, $\mathrm{RBC}$ count, MCV, and RDW, the best set of indices for differentiating 4 diagnoses. The study demonstrated that a set of linear discriminant functions based on routine hemogram data can effectively differentiate between $\alpha$-thalassemia, $\beta$-thalassemia, and IDA, with a high degree of accuracy.

As Eldibany et al. proposed, we started the classification type I (Table 2) with two functions and four outcomes, but the results obtained were poorer than those expected, mainly in 
TABLE 3: Distribution of predicted versus actual disease classification in the validation set applying the classification type I. Number of patients (column \%).

\begin{tabular}{|c|c|c|c|c|c|}
\hline \multirow{2}{*}{ Predicted diagnosis } & \multicolumn{2}{|c|}{ Actual diagnosis } & \multirow{2}{*}{ IDA } & \multirow{2}{*}{$\alpha$-thalassemia } & \multirow{2}{*}{ Tota } \\
\hline & Mixed & $\beta$-thalassemia & & & \\
\hline Mixed & $6(13.7)$ & $17(27)$ & $13(2.6)$ & $2(12.5)$ & 38 \\
\hline$\beta$-thalassemia & $3(6.8)$ & $19(30.1)$ & $3(0.6)$ & 0 & 25 \\
\hline IDA & $13(29.5)$ & $2(3.2)$ & $355(70.3)$ & $3(18.7)$ & 373 \\
\hline$\alpha$-thalassemia & $22(50)$ & $25(39.7)$ & $134(26.5)$ & $11(68.8)$ & 192 \\
\hline Total & 44 & 63 & 505 & 16 & \\
\hline
\end{tabular}

IDA: iron deficiency anemia.

TABLE 4: Distribution of predicted versus actual disease classification in the validation set applying the classification type II. Number of patients (column \%).

\begin{tabular}{lcc}
\hline Predicted diagnosis & \multicolumn{2}{c}{ Actual diagnosis } \\
& $\begin{array}{c}\text { Acquired anemia } \\
(n=505)\end{array}$ & $\begin{array}{c}\text { Genetic anemia } \\
(n=123)\end{array}$ \\
\hline $\begin{array}{l}\text { Acquired anemia, } \\
\text { IDA }(n=436)\end{array}$ & $412(81.6)$ & $24(19.5)$ \\
Genetic anemia $(n=192)$ & $93(18.4)$ & $99(80.5)$ \\
\hline
\end{tabular}

IDA: iron deficiency anemia.

case of $\beta$-thalassemia ( $30 \%$ correctly identified). The correct classification for $\alpha$-thalassemia in both studies was around $70 \%$, a high rate that could be taken into account in endemic areas. In the mixed group $29.5 \%$ were misclassified as IDA, so $71.5 \%$ was recognized as genetic anemia.

Nevertheless, the $\mathrm{HbA}_{2}$ analysis is the gold standard in the diagnosis of thalassemia. The increase of $\mathrm{HbA}_{2}$ is the most relevant diagnostic characteristic of $\beta$-thalassemia carriers and is low or within reference range in $\alpha$-thalassemia patients [18].

We tried to improve the diagnostic performances and the predictor parameters selected, $\mathrm{RBC}, \mathrm{Hb}, \mathrm{MCV}, \mathrm{MCH}$, and RDW, which were used in one function with only two outcomes: acquired anemia (IDA) and genetic anemia.

The results improved, and $80.5 \%$ with genetic anemia were detected, $87.9 \% \beta$-thalassemia carriers, $83.3 \% \alpha$-thalassemia carriers, and $72.1 \%$ in the mixed group were correctly classified, so we propose a diagnostic based on MDA and $\mathrm{HbA}_{2}$ analyses.

The samples classified in the latter group by MDA are selected for $\mathrm{HbA}_{2}$ measurement; based on the values obtained and the presence or not of $\mathrm{Hb}$ variants, molecular analysis can be performed, but the results obtained in the mixed group suggest that the mixed thalassemia and iron deficiency status remain the most difficult to detect, and 19.5\% of the patients with genetic anemia were misclassified as IDA.

It is difficult to talk about thalassemia globally since the social situation and the health systems are diverse anywhere in the world. In the developing countries, where these diseases are endemic, represent a problem of public health, but, in the developed countries with the general budgetary reductions, the presumptive identification of hemoglobin disorders must rely on inexpensive methods of detection, to allow an efficient use of the resources: a good system for screening can help, allowing efficiently selecting samples for further analysis to confirm the disease.

\section{Conclusions}

The above-described system is aimed at screening for thalassemia in samples for which full blood count parameters have been technically and clinically validated prior to the interpretive process. Its main aim is to focus attention and efforts on those samples requiring further investigation for a complete diagnosis.

In an era where demands on laboratories are ever increasing and funding and staffing levels are generally below the desired level, the implementation of a system which reduces staff time and improves result turnaround times is greatly desired. The implementation of a system such as the one we have described will introduce a safe and cost-effective method to minimize the amount of time specialized biomedical scientist spent on analysing results in which no abnormalities are present.

A drawback of this study is the fact that only heterozygous carries were included; the reason was the low prevalence of hemoglobinopathies in our area; perhaps other authors may consider the new approach and would try to verify our findings in areas of high prevalence of these diseases.

\section{References}

[1] P. C. Giordano, M. J. Bouva, and C. L. Harteveld, "A confidential inquiry estimating the number of patients affected with sickle cell disease and thalassemia major confirms the need for a prevention strategy in The Netherlands," Hemoglobin, vol. 28, no. 4, pp. 287-296, 2004.

[2] A. Mosca, R. Paleari, G. Ivaldi, R. Galanello, and P. C. Giordano, "The role of haemoglobin $\mathrm{A}_{2}$ testing in the diagnosis of thalassaemias and related haemoglobinopathies," Journal of Clinical Pathology, vol. 62, no. 1, pp. 13-17, 2009.

[3] J. F. Hair, W. C. Black, B. J. Babin, and R. E. Anderson, Multivariate Data Analysis, Pearson Prentice Hall, 7Th edition, 2010.

[4] J. D. Cook, "Diagnosis and management of iron-deficiency anaemia," Best Practice and Research, vol. 18, no. 2, pp. 319-332, 2005. 
[5] S. L. Thein and R. S. Wallace, "The use of synthetic oligonucleotides as specific hybridation probes in the diagnosis of genetic disorders," in Human Genetic Diseases, A Practical Approach, K. E. Davis, Ed., pp. 33-50, IRL Press, Oxford, UK, 1986.

[6] H. H. Kazazian Jr., “The Thalassemia syndromes: molecular basis and prenatal diagnosis in 1990," Seminars in Hematology, vol. 27, no. 3, pp. 209-228, 1990.

[7] D. J. Weatherall and J. B. Clegg, "Inherited haemoglobin disorders: an increasing global health problem," Bulletin of the World Health Organization, vol. 79, no. 8, pp. 704-712, 2001.

[8] D. A. Rathod, A. Kaur, V. Patel et al., "Usefulness of cell counterbased parameters and formulas in detection of $\beta$-thalassemia trait in areas of high prevalence," American Journal of Clinical Pathology, vol. 128, no. 4, pp. 585-589, 2007.

[9] M. Sirdah, I. Tarazi, E. Al Najjar, and R. Al Haddad, "Evaluation of the diagnostic reliability of different RBC indices and formulas in the differentiation of the $\beta$-thalassaemia minor from iron deficiency in Palestinian population," International Journal of Laboratory Hematology, vol. 30, no. 4, pp. 324-330, 2008.

[10] E. Urrechaga, "Discriminant value of \% microcytic/\% hypochromic ratio in the differential diagnosis of microcytic anemia," Clinical Chemistry and Laboratory Medicine, vol. 46, no. 12, pp. 1752-1758, 2008.

[11] M. A. Ehsani, E. Shahgholi, M. S. Rahiminejad, F. Seighali, and A. Rashidi, "A new index for discrimination between iron deficiency anemia and beta-thalassemia minor: results in 284 patients," Pakistan Journal of Biological Sciences, vol. 12, no. 5, pp. 473-475, 2009.

[12] E. Urrechaga, L. Borque, and J. F. Escanero, "The role of automated measurement of RBC subpopulations in differential diagnosis of microcytic anemia and $\beta$-thalassemia screening," American Journal of Clinical Pathology, vol. 135, no. 3, pp. 374379, 2011.

[13] P. Han and K. P. Fung, "Discriminant analysis of iron deficiency anaemia and heterozygous thalassaemia traits: a 3-dimensional selection of red cell indices," Clinical and Laboratory Haematology, vol. 13, no. 4, pp. 351-362, 1991.

[14] S. R. Amendolia, A. Brunetti, P. Carta et al., "A real-time classification system of thalassemic pathologies based on artificial neural networks," Medical Decision Making, vol. 22, no. 1, pp. 18-26, 2002.

[15] J. Kneifati-Hayek, W. Fleischman, L. H. Berstein, A. Riccioli, and R. Belleuve, "A model for automated screening of thalassemia in hematology (Math study)," Laboratory Hematology, vol. 13, no. 4, pp. 119-123, 2007.

[16] Y. Daniel, B. Witchlow, and A. Almeida, "Automated computer result reporting for haemoglobinopathy screening," Clinical and Laboratory Haematology, vol. 26, no. 1, pp. 21-24, 2004.

[17] M. M. Eldibany, K. F. Totonchi, N. J. Joseph, and D. Rhone, "Usefulness of certain red blood cell indices in diagnosing and differentiating thalassemia trait from iron-deficiency anemia," American Journal of Clinical Pathology, vol. 111, no. 5, pp. 676682, 1999.

[18] A. Mosca, R. Paleari, G. Ivaldi, R. Galanello, and P. C. Giordano, "The role of haemoglobin $\mathrm{A}_{2}$ testing in the diagnosis of thalassaemias and related haemoglobinopathies," Journal of Clinical Pathology, vol. 62, no. 1, pp. 13-17, 2009. 


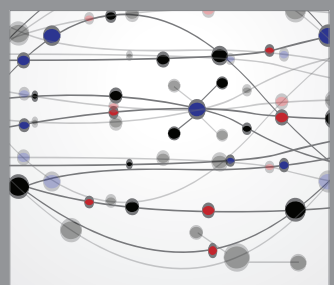

The Scientific World Journal
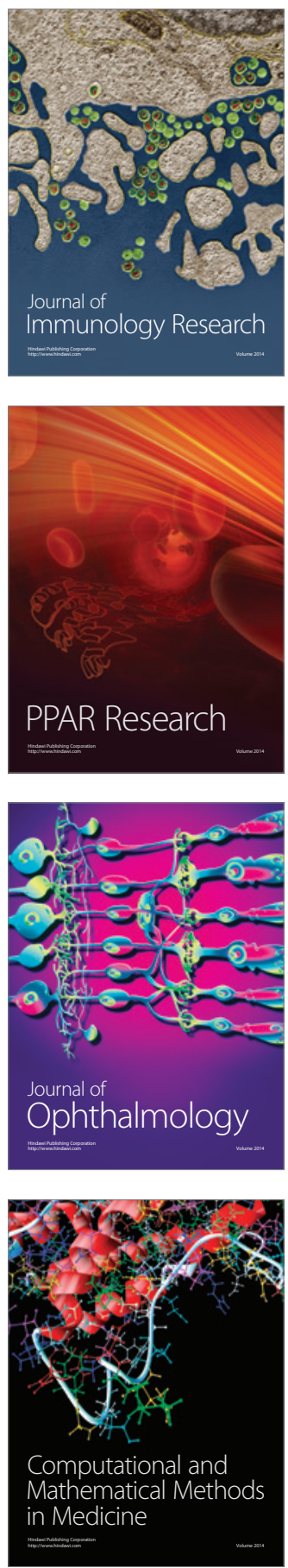

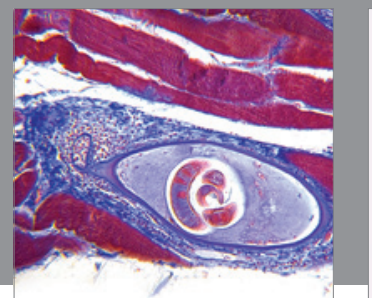

Gastroenterology

Research and Practice
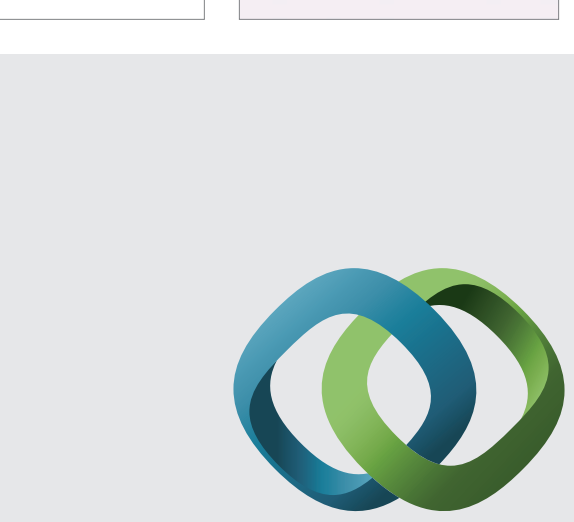

\section{Hindawi}

Submit your manuscripts at

http://www.hindawi.com
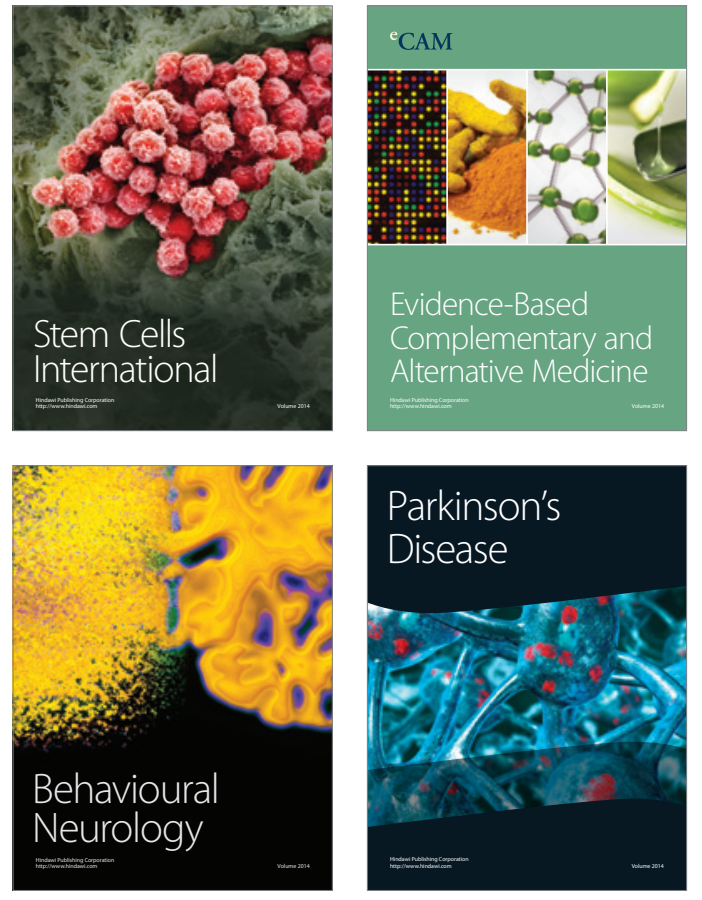
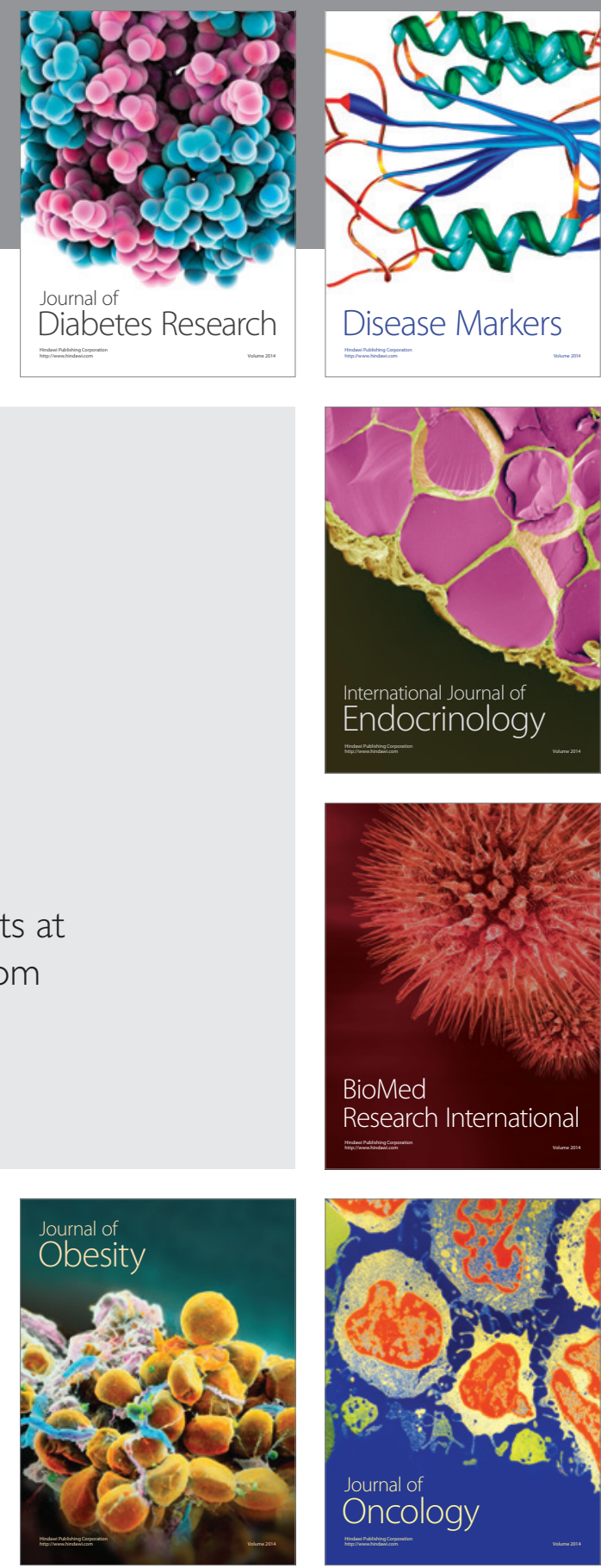

Disease Markers
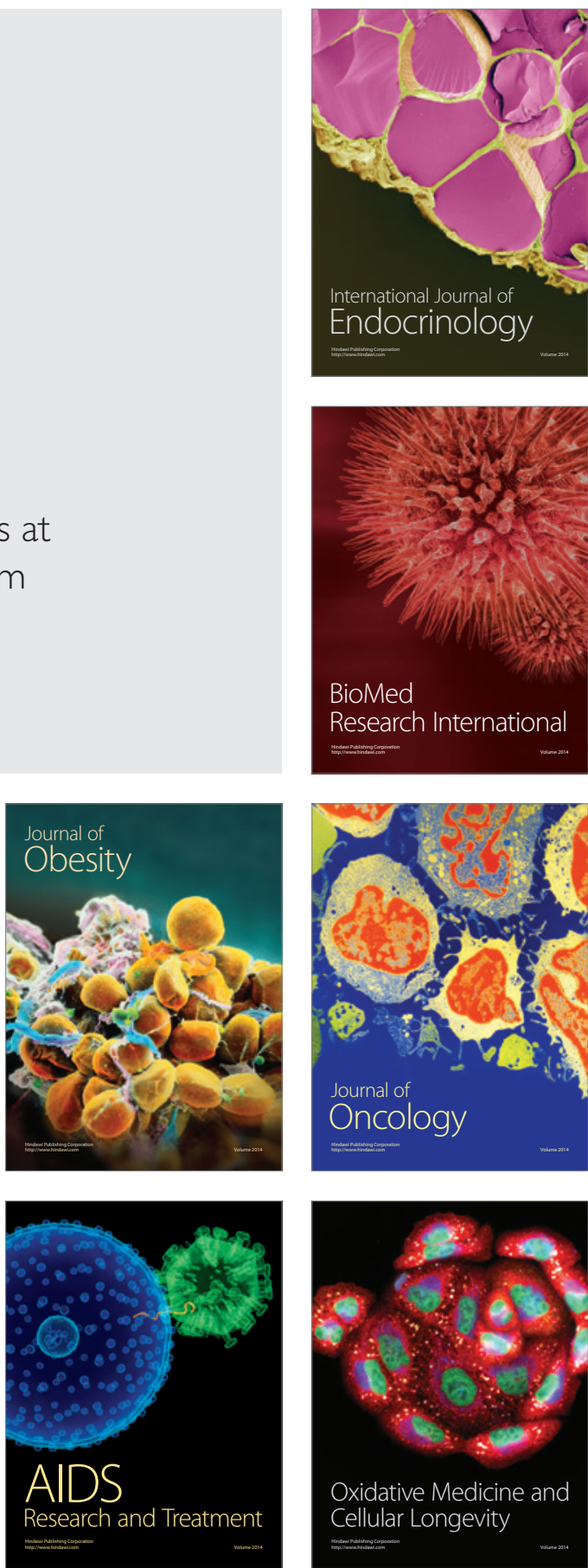